\title{
Pharmacovigilance of thalidomide in the Brazilian Health System and patient safety
}

\author{
Paula Lana de Miranda Drummond ${ }^{\circledR 1,2}$, Roberta Márcia Marques dos Santos², \\ Cristine de Araújo Silva ${ }^{2}$, Cristiane Aparecida Menezes de Pádua ${ }^{1}$
}

${ }^{1}$ Departamento de Farmácia Social, Faculdade de Farmácia, Universidade Federal de Minas Gerais, Belo Horizonte, MG, Brazil, '2Divisão de Assuntos Regulatórios, Diretoria Industrial, Fundação Ezequiel Dias, Belo Horizonte, MG, Brazil

\begin{abstract}
In Brazil, thalidomide is manufactured by a public laboratory, distributed by the Unified Health System (SUS), and regulated by the National Health Surveillance Agency (Anvisa). Despite the concerns regarding the adverse effects of thalidomide, few drug utilization studies have been conducted to describe processes and outcomes related to this drug. The aim of this study was to elucidate the issues related to the utilization and control of thalidomide, and patient safety within the scope of SUS. In this cross-sectional study, we evaluated the articulation between an outpatient dermatology service of a referral hospital in infectology, the manufacturer, and Anvisa. Four data sources were used: i) interviews with health professionals; ii) data from the Customer Service of the manufacturer, iii) data on adverse events reported to Anvisa, and iv) adverse events identified in outpatient service. Most health professionals interviewed knew the major thalidomide-related adverse effects. None of them ever reported adverse events to Anvisa or contacted the Customer Service. For over three years, there were 330 calls concerning thalidomide at Customer Service, $7 \%$ of which were related to adverse events. During a period of six years, Anvisa was notified of only 15 adverse events. Health professionals were aware of the adverse events associated with thalidomide, but not the necessity to report them. The low number of notifications recorded by Anvisa and the information obtained from Customer Service show that pharmacovigilance remains incipient. A pharmacovigilance system that integrates all the services associated with thalidomide is required to strengthen this activity within the SUS to improve patient safety.
\end{abstract}

Keywords: Thalidomide. Patient safety. Notification. Pharmacovigilance.

\section{INTRODUCTION}

Thalidomide is a drug whose main pharmacological activities include sedative, immunomodulatory, and antiinflammatory effects, inhibition of TNF- $\alpha$ production,

*Correspondence: P. L. de M. Drummond. Divisão de Assuntos Regulatórios. Diretoria Industrial. Fundação Ezequiel Dias. Rua Conde Pereira Carneiro, 80. Bairro Gameleira, Belo Horizonte, CEP 30510-010, MG, Brazil, Phone: (31)3314-4899 / 4833. E-mail: paulalana.86@gmail.com. and antiangiogenic activity (Patil, Bhise, 2003). In Brazil, the use of thalidomide is approved for the treatment of erythema nodosum leprosum (ENL), idiopathic aphthous ulcers in individuals who are HIV positive, multiple myeloma, lupus, graft versus host disease, and myelodysplastic syndrome (ANVISA, 2011a).

In view of the broad therapeutic uses and, on the other hand, of the recognized teratogenic effects of thalidomide, the need of monitoring its utilization becomes crucial. Since 2007, the Food and Drug Administration (FDA) of the United States requires 
the development of risk evaluation and mitigation strategies (REMS) programs for the approval of new drugs or drugs of known risk. Thus, the Celgene Corporation has been implemented the thalidomide (and congeners) REMS program including elements to assure safe use (ETASU) by informing patients and health professionals of its serious risks and safeuse conditions of the drug (Brandenburg et al, 2017). In Brazil, the use of thalidomide has been subjected to special control since 1994. The most recent Resolution by the Brazilian Health Regulatory Agency (Anvisa), in 2011, established: i) exclusive manufacturing by public laboratories, ii) use subject to special control, iii) prescription with notification of special prescription followed by a term of responsibility and clarification, subscription of iv) prescribers and v) patients by the States Secretaries of Health, and vi) accreditation of the dispensing units by health surveillance system. According to this Resolution, health professionals must be periodically and permanently trained on the risks and standards involving the use of thalidomide. In addition, they must be informed that notification to Anvisa of thalidomide-related adverse events is compulsory and that the treatment of women at childbearing age requires obligatory use of two contraceptive methods and pregnancy tests before and during the treatment (ANVISA, 2011a).

Currently, thalidomide is produced in Brazil by the public laboratory Fundação Ezequiel Dias - Funed, in Minas Gerais, exclusively to government programs according to the demand of the Ministry of Health, which distributes the medicine to the State Secretaries of Health, and they then distribute it to the municipalities, to ensure that dispensing to the registered patients is carried out (FUNED, 2015).

In 2016, the Ministry of Health purchased 6,334,560 thalidomide tablets (equivalent to 63,345.6 daily defined doses - DDD (according to Brazilian logistics system, in 06 nov 2015). In the same year, there were 2,238 patients registered to receive thalidomide in the state of Minas Gerais (equivalent to the consumption of approximately $5 \%$ of the tablets in the country). The Eduardo de Menezes Hospital, reference in infectology, was responsible for dispensing approximately $13 \%$ of thalidomide tablets in the state in 2014 and approximately 14\% in 2015, making it the main drug dispensing unit of thalidomide in Minas Gerais (according to Ofício DMEST-SAF-SES-MG N 12/2016). Most of the tablets dispensed from this hospital are for patients with leprosy for ENL treatment.
The hospital is part of the "Sentinel Network", in which accredited hospitals must notify Anvisa the occurrence of adverse events related to health products (FHEMIG, 2015; ANVISA, 2017; ANVISA, 2011b).

Anvisa manages a national system of notifications - which used to be called Notivisa and now has been replaced by Vigimed - developed to receive notifications of incidents, adverse events, and technical complaints related to the use of products and services under sanitary surveillance. The notifications are analyzed and classified by the health surveillance according to severity, causality, predictability, and associated risk. Adverse events (suspected or confirmed cases) and technical complaints related to the use of thalidomide must be notified compulsorily and immediately to Anvisa by health professionals and healthcare services involved in controlling the use of the drug. Patients, family members, and caregivers can also notify (ANVISA, 2011a; ANVISA, 2017).

The aim of the present study was to describe the issues associated with the utilization of thalidomide and its control in Brazil from the perspective of public laboratory that manufactures the medicine, an outpatient service of a referral hospital in infectology, and the health regulatory agency, focusing on patient safety.

\section{MATERIAL AND METHODS}

\section{Study Design}

This was a cross-sectional study, which included the diagnosis of functioning and articulation between an outpatient dermatology service of a referral hospital in infectology, the public laboratory manufacturer of the medicine, and the health regulatory agency, involved in the control of thalidomide use, with safety and monitoring of patients under the Unified Brazilian Health System - SUS.

\section{Ethical Aspects}

The study was approved by the Research Ethics Committees of the participating institutions (54594916.4.0000.5149 - Universidade Federal de Minas Gerais - UFMG and 54594916.4.3001.5124 - Eduardo de Menezes Hospital). The participation in the study was voluntary and consented by signing the informed consent form, guaranteeing the confidentiality of the information collected. 


\section{Data source and data collection}

Four different data sources were used in the study - interviews with health professionals, data on spontaneous reporting of thalidomide adverse events from the Customer Service Department of the public manufacturer and from the Pharmacovigilance Department of Anvisa, and Identification of Adverse Event in Outpatient Service. A brief description of the centers, of the data collection and of the study variables is presented below.

\section{Outpatient Dermatology Service of a \\ Referral Hospital in Infectology}

The referral hospital in infectology has a multiprofessional health team, comprising doctors, nurses, physiotherapists, occupational therapists, and pharmacists, all involved in the care of patients using thalidomide. From September to October 2016, the health professionals involved in the outpatient care of patients under treatment with thalidomide were interviewed through a questionnaire related to patient care, adverse events to thalidomide, and the Anvisa Resolution - RDC 11/2011 (ANVISA, 2011a).

A standardized questionnaire was applied to the health professionals containing questions related to i) patient care (e.g. Do you guide the patient about thalidomide treatment?); ii) treatment with thalidomide (e.g. Do you know the main indications for using thalidomide?); iii) legal aspects of thalidomide use (e.g. Does thalidomide have a special prescription?); iv) notification of adverse events (e.g. Have you ever notified an adverse reaction?) and v) awareness about the specific legislation) (e.g. Do you know that there is specific legislation on the control of thalidomide?) (Table 1).

A pilot study was conducted by interviewing one professional from each area to adapt the tool and data collection procedures.

TABLE I - Interviews with health professionals from referral hospital

Questions addressed

\section{Positive answers}

$$
\mathbf{n}=\mathbf{2 0}
$$

$\%$

Have you ever been trained in the use / prescription of thalidomide?

18

90

Do you guide the patient about thalidomide treatment?

17

85

Do you know the main adverse reactions of thalidomide?

16

80

Do you record adverse reactions?

12

60

0

0

Have you ever contacted the Customer Service (SAC) of the manufacturer?

0

$\mathbf{n}=15^{*}$

$\%$

Do you know the main indications for using thalidomide?

15

100

Is thalidomide a controlled drug?

15

100

Does thalidomide have a special prescription?

15

100

Do you know that there is specific legislation on the control of thalidomide?

9

60

Do you guide the use of condoms for male patients?

1

*Only applicable to physicians, pharmacists and pharmacy technicians

Source: health professionals' interviews 


\section{Public Manufacturer Laboratory}

Currently, the manufacturer develops thalidomide pharmacovigilance by receiving patients' spontaneous reporting of adverse events through the Customer Service Department. This service is linked to the pharmacovigilance of the laboratory, and is responsible for attending the population and health professionals concerning various issues related to the products, as well as technical complaints and spontaneous reports of adverse events. Once an adverse event is received, associated or not to the product, the public laboratory follows-up the patient, by phone calls, until a clinical outcome, or the patient himself agrees that monitoring is no longer necessary. During this follow-up, the laboratory requests the contacts of doctors, nurses and pharmacists who directly assist the patient, so that all relevant additional information is obtained for the performance of a technical evaluation. All adverse events associated or not with the use of the product are also informed to Anvisa through the national notification system and compiled into a Periodic Report of Phamacovigilance of the product.

From 2014 to 2016, the database of the Customer Service Department of the manufacturer laboratory of thalidomide was analyzed. All calls related to the use of thalidomide, considering all indications, were counted and categorized according to the reason for contact.

\section{Brazilian Health Regulatory Agency}

The Anvisa Pharmacovigilance Department provided the data on adverse events associated with the use of thalidomide, referring to any indication of use, reported spontaneously through the system of notification - Notivisa, from January 2010 to May 2016, when the request was made, through "Ofício 08/2016 GFARM/GGMON/ANVISA Notification of Adverse Events of Thalidomide in Notivisa".

\section{Identification of Adverse Event in Outpatient Service}

Data on adverse events to thalidomide was obtained through review of medical charts and interview of 110 patients with erythema nodosum leprosum in a crosssectional study previously carried out by the authors (Drummond, 2019). Interviews were carried out between July and October 2016 and adverse events to thalidomide were reviewed in the medical records up to 12 months preceding the interviews. The study results were presented to appraise differences in the number of "potential" adverse events according to the available data sources.

\section{Statistical analyses}

A descriptive analysis was performed by calculating absolute and relative frequencies of the study variables. Data management and statistical analyses were performed through the Epi Info ${ }^{\mathrm{TM}}$, version 7.2.

\section{RESULTS}

\section{Interviews with Health Professionals}

Twenty health professionals were interviewed - nine physicians, two pharmacists, four pharmacy technicians, two physiotherapists, one occupational therapist, and two nurses. The answers obtained from the interviews are presented in Table I.

With the exception of pharmacists, all professionals interviewed participated in at least one training related to the use of thalidomide. Most professionals mentioned that the training was conducted indirectly through a course on leprosy, which addressed the treatment of ENL, and directly through training on the legislation of thalidomide given by pharmacists. Both trainings were through the initiative of hospital employees.

Most participants reported of providing some guidance on the treatment with thalidomide to patients. In this hospital, patient advice was assigned as the responsibility of the physician during consultation. The use of contraceptive methods for women at childbearing age and non-sharing of medicine with another person were the main advices mentioned by physicians. During dispensation, new patients were instructed by pharmacy technicians not to share the medication and to use it according to the medical recommendation.

The adverse events were recorded in medical records by physicians and physiotherapists, who were responsible by patients' disabilities prevention monitoring. None of the professionals interviewed reported of having notified adverse events to Anvisa or used the Consumer Service of the manufacturer laboratory. The availability of a specific service to monitor adverse events or pharmacovigilance of patients (inpatients or outpatients) using thalidomide in the hospital has not been reported.

All the professionals answered positively to the knowledge of the main use indications of thalidomide 
and to the legal questions related to the control of its use. The physicians reported of using the special prescription for thalidomide, referring to the number of tablets for 30 days of treatment, accompanied by the term of responsibility and clarification. Each physician had his/ her own prescription booklet for thalidomide.

Pharmacists dispensed thalidomide according to the number of tablets prescribed and recorded it in the patient's registry in the state electronic system. Only one of the professionals reported advising male patients about condom use.

\section{Customer Service of the Public Manufacturer Laboratory}

The contacts concerning the use of thalidomide were related to adverse events, technical complaints due to suspicion of quality deviation, complaints, and requests for information (including mode of use and where to obtain thalidomide) (Figure 1, Table II). The main reason for contact was the search for information $(89.4 \%)$ and the attendance related to possible adverse events represented $7 \%$ of the calls during the study period.

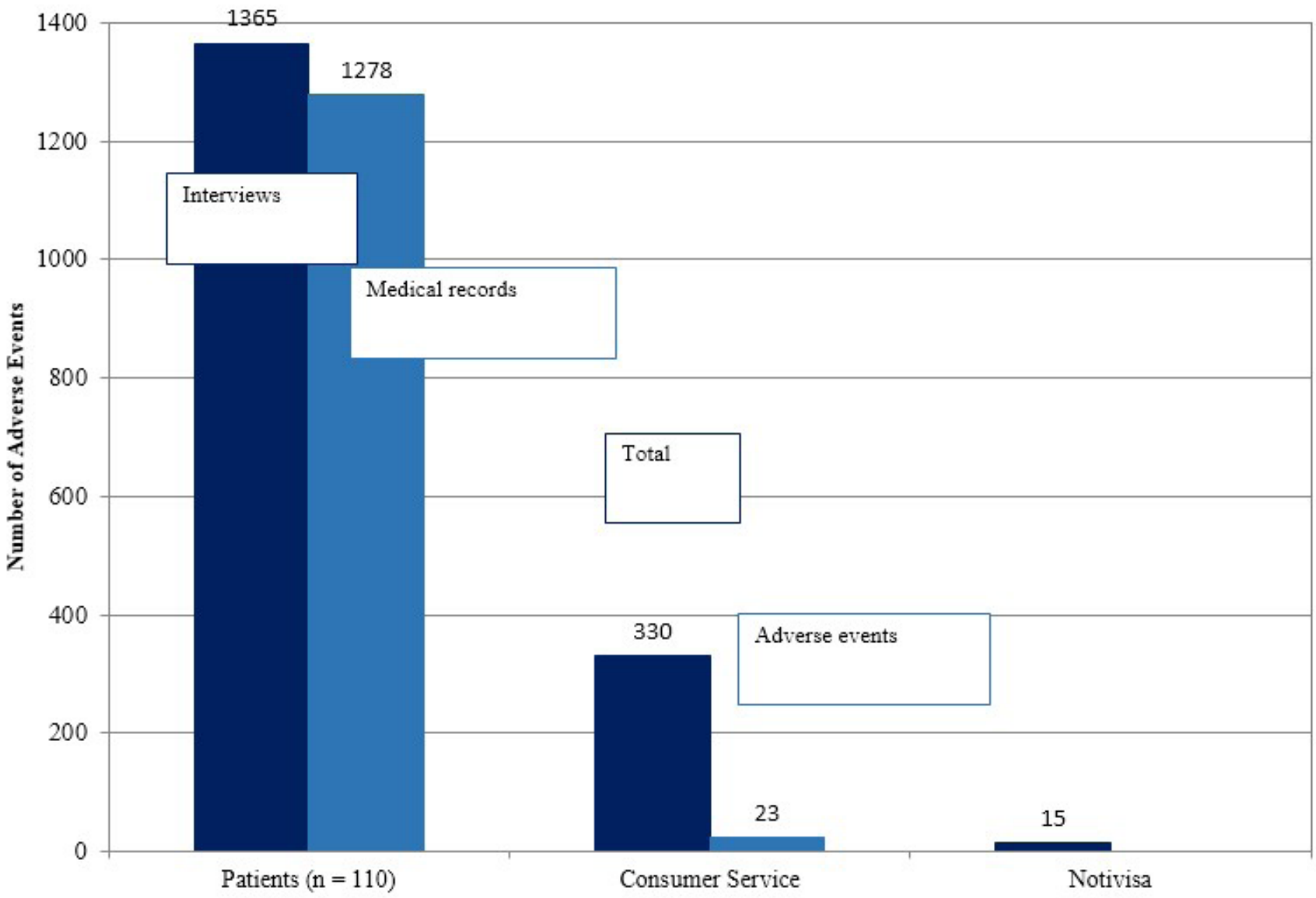

FIGURE 1 - Adverse events associated to thalidomide according to data source. 
TABLE II - Reason for consulting the Custumer Service Departament

\begin{tabular}{lcccc}
\hline Reason for contact & $\mathbf{2 0 1 4}$ & $\mathbf{2 0 1 5}$ & $\mathbf{2 0 1 6}$ & Total (\%) \\
\hline Adverse event & 3 & 10 & 10 & $23(7.0)$ \\
Technical complaint & 1 & 4 & 2 & $7(2.1)$ \\
Complaint & 4 & 1 & 0 & $5(1.5)$ \\
Information & 41 & 45 & 209 & $295(89.4)$ \\
Total & 49 & 60 & 221 & $330(100.0)$ \\
\hline
\end{tabular}

Source: Customer Service Department of the public manufacturer of thalidomide

\section{Data from Notivisa/ Brazilian Health Regulatory Agency}

From the data provided by Anvisa, 15 adverse events related to the use of thalidomide were reported, of which $10(66.7 \%)$ were classified as serious (Table III). Three (20\%) of the adverse events reported corresponded to peripheral neuropathy, and one of them with certain causality. Another adverse event of certain causality was seizure, reported once.

TABLE III - Notification of adverse events related to the use of thalidomide $(\mathrm{n}=15)$

\begin{tabular}{lccc}
\hline Adverse reaction & $\mathbf{n}(\mathbf{\%})$ & Severity & Causality \\
\hline Sinus bradycardia & $1(6.7)$ & Not serious & Probable \\
Constipation & $2(13.3)$ & Not serious & Possible \\
Seizures & $1(6.7)$ & Serious & Certain \\
Pharmacodermia & $1(6.7)$ & Serious & Possible \\
& & & 1.Certain \\
Peripheral & & & $\begin{array}{c}\text { 2. Possible } \\
\text { neuropathy }\end{array}$ \\
& $3(20.0)$ & Serious & (continuing)
\end{tabular}

TABLE III - Notification of adverse events related to the use of thalidomide $(\mathrm{n}=15)$

\begin{tabular}{lccc}
\hline Adverse reaction & $\mathbf{n}(\mathbf{\%})$ & Severity & Causality \\
\hline $\begin{array}{l}\text { Macular- } \\
\text { papular rash }\end{array}$ & $1(6.7)$ & Serious & Probable \\
Polyneuropathy & $1(6.7)$ & Serious & Possible \\
Allergic reaction & $1(6.7)$ & Serious & Possible \\
$\begin{array}{l}\text { Stevens Johnson } \\
\text { Syndrome }\end{array}$ & $1(6.7)$ & Serious & Possible \\
$\begin{array}{l}\text { Somnolence } \\
\text { Deep vein }\end{array}$ & $2(13.3)$ & Not serious & Probable \\
thrombosis & $1(6.7)$ & Serious & Probable \\
\hline
\end{tabular}

Source: Notivisa, Anvisa (2016).

\section{Adverse Events identified in Outpatient Service}

A total of 1365 and 1278 adverse events were observed according to patient interviews (self-report) and review of their medical charts, respectively. These amounts were quite different by comparing with the data from Notivisa/Anvisa and Customer Service of the Public Manufacturer Laboratory (Figure 1).

\section{DISCUSSION}

In this study, we aimed to relate the care of patients using thalidomide in the outpatient dermatology service of a referral hospital in infectology, with the frequency of adverse events notified to Anvisa and to the Customer Service of the public laboratory, which manufactures the medicine in Brazil. We observed a low rate of adverse events reporting (potentially harmful to patient and possibly preventable) in all services and some health professionals who were not entirely aware of thalidomide legislation and do not advise on the importance of condom use by men during the treatment with thalidomide.

In a study carried out by Oliveira et al (2013), where they evaluated all notifications of adverse events recorded in Notivisa from 2006 to 2011, the number of drug-related notifications increased significantly 
from 2007, and the main notifiers were the "Sentinel Network" hospitals.

Although our study focused on a hospital belonging to the sentinel network, no service was found within this hospital that was concerned with reporting the adverse events associated with thalidomide. Information on adverse events is recorded in the patients' medical charts, but they are not notified to Anvisa and/or the manufacturer laboratory. The notification in the national notification system and/or via the Customer Service of the manufacturer laboratory is important to subsidize the adoption of pharmacovigilance measures (ANVISA, 2017b).

The "Sentinel Network" was created due to Anvisa's difficulty in receiving notifications of adverse events, grievances, and technical complaints about health products. This is due to the lack of practice of health professionals in reporting the occurrences of adverse events involving health products in Brazil (ANVISA, 2017a). The centralization of notification activity in the "Patient Safety Center" - NSP of the referral hospital in infectology, in the context of the National Patient Safety Program, is discussed as an option to increase the quantity and quality of notifications. After the creation of this Program and the deployment of 2,333 NSP in different locations in Brazil, from 2014 to 2017, there has been a significant increase in the number of notifications of adverse events (Ministério da Saúde, 2017). Mendes (2008) conducted a survey of adverse event notifications in the state of Rio de Janeiro and concluded that pharmacists are the health professional that mostly notifies and that hospitals were the main notifying institutions; therefore, probably the highest percent of notifications would be performed by professionals working in hospital pharmacies. Pharmaceutical assistance becomes increasingly important in patient care. However, even with advances in this area, including the public health network in Brazil, several problems persist and the link between the pharmaceutical service and curative health model still remains. This makes it difficult for pharmacists to advice their patients, and the path to be followed is long to ensure that pharmaceutical care, at least at the outpatient level, fulfills its role satisfactorily (Vieira, 2010). In the present study, we identified that patients using thalidomide were registered as SUS users, and also when thalidomide is dispensed to patients. However, there was no follow-up of these patients developed by pharmacists.
In our previous study (Drummond, 2019), we performed an active search for the adverse events in patients with leprosy using thalidomide at the same outpatient dermatology service of the present study. We found 1,278 adverse events recorded in the medical records of 110 patients within a period of one year of medical attendance. Comparing this number of adverse events recorded in the medical records with the 23 spontaneous reports in a period of three years (2014 to 2016) to the Customer Service of the manufacturer laboratory and with the 15 notifications recorded in Notivisa in approximately six years (see Figure 1), it is noted that health professionals have not yet incorporated the notification activity in their work routine. Early pharmacovigilance training, integrated with undergraduate, postgraduate, and professional health curricula could contribute to create awareness and consider pharmacovigilance as a routine activity and necessary for patient safety at the beginning of careers (Isah et al, 2012; Elshafie, Roberti, Zaghloul, 2018).

It was also observed that the training related to the legislation that had already been offered to the hospital staff, started from the initiative of the outpatient pharmacists, who had not previously received training from the Ministry of Health or from the Secretariats of Health. This suggests the absence of standardized training for health professionals. It would be important to reinforce the need for guidance of the male patient on the use of condoms during treatment. Thalidomide's legislation and the package leaflet recommend the use of a condom as a preventive measure and studies demonstrate the presence of thalidomide in semen of patients taking the drug (ANVISA, 2011a, Teo et al, 2001, FUNED, 2014).

Pharmacovigilance systems in developing countries, such as Brazil, rely mainly on spontaneous reporting and find barriers with its implementation, such as underreporting, resource constraints, and limited regulatory capacity (Isah et al, 2012; Elshafie, Zaghloul, Roberti, 2017). Some interventions have already been identified as effective tools to improve reporting, including educational activities, simpler and more easily available forms, facilitated notification procedures, feedback, and incentives for notifiers (Elshafie, Roberti, Zaghloul, 2018).

The pharmaceutical industry has the primary responsibility for the safety of medicines. In the US, pharmacovigilance of high-risk drugs, such as thalidomide, has been strengthen by REMS program 
(Brandernburg, et al, 2017), which includes information communicated to and/or required activities to be undertaken by health care providers, pharmacists and patients. This strategy involves patient registration, which allows informing, educating and monitoring patients with the aim of preventing patient harm. In Brazil, the government (SUS) is responsible for the registration of patients using thalidomide, being the data not available for patient monitoring, since there isn't an integrated data network where patients' information could be shared between the health surveillance and the public manufacturer. Pharmacovigilance of thalidomide has been developed by the manufacturer laboratory through the Customer Service and by Anvisa trough the national notification system, separately and in a passive manner.

We acknowledge the importance of drug users as notifiers, and it has been shown that notifications submitted directly by them can aid in the detection of drug safety signals (Hammond, Rich, Gibbs, 2007). By this approach, patients can participate actively in generating knowledge about the safety profile of medicines (OPAS, 2011). Despite this, the Brazilian manufacturer's Customer Service of thalidomide is underused. An effective dissemination of this service to the population and health professionals may be an alternative to increase the number of spontaneous reports. In addition to the Ministry of Health and State Health Secretariats, the Brazilian manufacturer could provide training to health professionals, as it is done by the laboratory manufacturer of thalidomide in the United States. And a data network could be developed to integrate services pharmacovigilance actions.

Notification is the main object of work in a pharmacovigilance program, and it is the shared responsibility of notifying institutions, health professionals, and users of medicines (Mendes, 2008). The effective involvement of health professionals from the public and private sectors, pharmaceutical industries, academic institutions, and general public is necessary to ensure a safe environment for drug therapy (Olsson, Pal, Dodoo, 2015).

\section{CONCLUSION}

The "thalidomide tragedy" in the 1960s was the milestone for commencing the pharmacovigilance actions worldwide (WHO, 2004). However, even in the face of the stigma of teratogenicity, the serious adverse events associated with its use and the high level of control required, the pharmacovigilance of this drug remains incipient, especially in the areas addressed in this study, without institutionalized follow-up of patients being treated. We noticed the existence of a culture of underreporting in Brazil leading to lack of information on the adverse events induced by thalidomide, which remains in medical records. Added to this is the absence of dialogue between health service providers, outpatient departments, and industrial and regulatory authorities, on health-related actions to be taken to mitigate the avoidable risks related to thalidomide. New indications for the use of thalidomide, such as myelodysplastic syndrome, have been approved, reinforcing the need of an effective monitoring of the drug nationwide. There is a need to implement a pharmacovigilance system that integrates all the actors involved in the safety of thalidomide users, to make the pharmacovigilance of thalidomide stronger and institutionalized under SUS with consequent quantitative and qualitative improvement of data and information safety of this medicinal product.

\section{ACKNOWLEDGMENTS}

We would like to acknowledge the health professionals at the Hospital Eduardo de Menezes, who were willing to participate and collaborate in our study. We thank Anvisa for providing the information requested for the study.

\section{REFERENCES}

Agência Nacional de Vigilância Sanitária (Brasil). Portaria $n^{\circ}$ 1.693, de 08 de novembro de 2011. Dispõe sobre os critérios para credenciamento de instituições na Rede Sentinela. Diário Oficial da União 09 nov 2011, Seção 1 (b).

Agência Nacional de Vigilância Sanitária (Brasil). Rede Sentinela. Apresentação. Disponível em: http://www.anvisa. gov.br/servicosaude/hsentinela/historico.htm Acesso em: 23 maio 2017 (a).

Agência Nacional de Vigilância Sanitária (Brasil). Resolução RDC n ${ }^{\circ} 11$, de 22 de março de 2011. Dispõe sobre o controle da substância talidomida e do medicamento que a contenha. Diário Oficial da União 24 mar 2011; Seção 1 (a).

Agência Nacional de Vigilância Sanitária (Brasil). Sistema de Notificações em Vigilância Sanitária. Apresentação. Disponível em: http://www.anvisa.gov.br/hotsite/notivisa/ apresenta.htm Acesso em: 22 maio 2017. 
Brandenburg NA, Bwire R, Freeman J, Houn F, Sheehan P, Zeldis JB. Effectiveness of Risk Evaluation and Mitigation Strategies (REMS) for Lenalidomide and Thalidomide: Patient Comprehension and Knowledge Retention. Drug Saf. 2017;40(4):333-41.

Drummond PLM, Santos RMM, Carvalho GO, Menezes de Pádua CA. Adverse events in patients with leprosy on treatment with thalidomide. Rev Soc Bras Med Trop. 2019;52:e20180385. http://dx.doi.org/10.1590/0037-86820385-2018.

Elshafie S, Roberti AM, Zaghloul I. Pharmacovigilance in developing countries (part II): a path forward. Int J Clin Pharm. 2018; 40(4):764-768. doi: 10.1007/s11096-017-0588-2.

Elshafie S, Zaghloul I, Roberti AM. Pharmacovigilance in developing countries (part I): importance and challenges. Int J Clin Pharm. 2017;40(4):758-763. doi: 10.1007/s11096-0170570-z.

Fundação Ezequiel Dias. Institucional. História da Fundação. Disponível em: http://www.funed.mg.gov.br Acesso em: 03 nov 2015.

FUNED TALIDOMIDA. Responsável técnico: Juliana Souki Diniz. Belo Horizonte: Fundação Ezequiel Dias, 2014. Bula de remédio. Disponível em: http://www.funed.mg.gov.br/ talidomida/ Acesso em 14 jul 2019.

Fundação Hospitalar do Estado de Minas Gerais. Hospital Eduardo de Menezes. Disponível em: http://www. fhemig.mg.gov.br/atendimento-hospitalar/complexo-deespecialidades/hospital-eduardo-de-menezes Acesso em: 23 aug 2015 .

Hammond IW, Rich DS, Gibbs TG. Effect of consumer reporting on signal detection: using disproportionality analysis. Expert Opin. Drug Saf. 2007;6(6):705-12.

Isah AO, Pal SN, Olsson S, Dodoo A, Bencheikh RS. Specific features of medicines safety and pharmacovigilance in Africa. Ther Adv Drug Saf. 2012;3(1):25-34.
MENDES MCP. História da Farmacovigilância no Brasil. Revista Brasileira de Farmácia. 2008;89(3):246-51.

Ministério da Saúde (Brasil). Programa Nacional de Segurança do Paciente. Núcleo de Segurança do Paciente. Disponível em: http://portalsaude.saude.gov.br/index. php/o-ministerio/principal/secretarias/1243-sas-raiz/dahuraiz/dahu/seguranca-do-paciente/seguranca-do-paciente12/28065-nucleo-de-seguranca-do-paciente Acesso em: 03 jun 2017.

Oliveira JR, Xavier RMF, Santos Júnior AF. Eventos adversos notificados ao Sistema Nacional de Notificações para a Vigilância Sanitária (NOTIVISA): Brasil, estudo descritivo no período 2006 a 2011. Epidemiologia e Serviços de Saúde. 2013;22:671-8.

Olsson S, Pal SN, Dodoo A. Pharmacovigilance in resourcelimited countries. Expert Rev Clin Pharmacol. 2015;8(4): 449-60.

OPAS. Boas Práticas de Farmacovigilância para as Américas. Washinton DC., OPS 2011 (Red PARF Documento Técnico 5). Disponível em: http://apps.who.int/medicinedocs/ documents/s18625pt/s18625pt.pdf Acesso em 14 jui 2019.

Patil CR, Bhise SB. Re-emergence of thalidomide. Ind Jour Pharm, 2003;3,204-12.

Vieira FS. Assistência farmacêutica no sistema público de saúde no Brasil. Rev Panam Salud Publica. 2010;27(2): 149-56.

Teo SK, Harden JL, Burke AB, Noormohamed FH, Youle $\mathrm{M}$, Johnson MA, et al. Thalidomide is distributed into human semen after oral dosing. Drug Metab Dispos. 2001;29(10):1355-7.

WHO - World Health Organization. Perspectivas políticas de la OMS sobre medicamentos. La farmacovigilancia: garantía de seguridad en el uso de los medicamentos. Ginebra: Organización Mundial de la Salud, 2004. Disponínel em: https://apps.who.int/medicinedocs/fr/d/Js6166s/ Acesso em 14 jul 2019.

Received for publication on $05^{\text {th }}$ September 2018 Accepted for publication on $05^{\text {th }}$ August 2019 